\title{
Exploratory calcineurin inhibitor-free regimens in living-related kidney transplant recipients
}

R. Garcia ${ }^{1}$, P.G. Machado ${ }^{1}$, C.R. Felipe ${ }^{1}$, S.I. Park ${ }^{1}$, G.A. Spinelli, M.F. Franco ${ }^{2}$, H. Tedesco-Silva Jr. ${ }^{1}$ and J.O. Medina-Pestana ${ }^{1}$
${ }^{1}$ Divisão de Nefrologia, Hospital do Rim e Hipertensão, Universidade Federal de São Paulo, São Paulo, SP, Brasil ${ }^{2}$ Departamento de Patologia, Universidade Federal de São Paulo, São Paulo, SP, Brasil
Correspondence

H. Tedesco-Silva Jr.

Rua Borges Lagoa, 960

04038-002 São Paulo, SP

Brasil

Fax: +55-11-5087-8145

E-mail: heliotedesco@hrim.com.br

Publication supported by FAPESP. ......................

Received March 28, 2006 Accepted January 19, 2007

\begin{abstract}
Chronic allograft nephropathy is among the major causes of graft loss even in low-risk kidney transplant recipients and correlates with acute nephrotoxic events during the first year post-transplant. Therefore, calcineurin inhibitor-free regimens may improve patient and graft survival among recipients of living-related kidney transplants. To confirm this hypothesis, we evaluated the efficacy and safety of two calcineurin inhibitor-free regimens in 92 low-risk recipients of onehaplotype living-related kidney transplants. Immunosuppression consisted of tacrolimus, azathioprine and prednisone (group I, GI, N = 38), 2 doses of daclizumab, mycophenolate mofetil (MMF), and prednisone (GII, $\mathrm{N}=33$ ) and 2 doses of daclizumab, MMF, sirolimus and prednisone (GIII, $\mathrm{N}=21$ ). At 12 months, treatment failure (biopsy-confirmed acute rejection, graft loss or death) was higher in GII compared to GIII and GI (54.5 vs 24.0 vs $13.1 \%, \mathrm{P}<0.01$, respectively). In patients of black ethnicity the incidence of acute rejection was 25 vs 83.3 vs 20\% $(\mathrm{P}=0.055)$, respectively. Patient and graft survival was comparable. There were no differences in mean creatinine or calculated creatinine clearance at 12 months. Overall incidence of post-transplant diabetes mellitus (3.3\%) and cytomegalovirus disease $(4.3 \%)$ was similar in all groups. Further development of effective calcineurin inhibitor-free regimens should exclude patients of black ethnicity and may need full-induction therapy, perhaps with depleting agents, and concentration-controlled use of sirolimus and MMF.
\end{abstract}

Key words - Tacrolimus

- Mycophenolate mofetil

- Sirolimus

- Kidney transplantation

- Acute rejection

- Clinical trial

\section{Introduction}

Recipients of living kidney allografts consistently demonstrate superior graft survival compared to recipients of deceased donors (1). Younger and healthy donors, better HLA matching, less ischemia/reperfusion injury and shorter time on dialysis may account for these findings $(1,2)$. Nevertheless, even among living donor kidney transplant recipients, major causes of graft loss are chronic allograft nephropathy and death with a functioning graft (1). Chronic allograft nephropathy correlates with the occurrence of acute 
nephrotoxic events during the first year posttransplant. In addition, since renal function is closely related to long-term kidney graft survival (3) and is a strong risk factor for cardiovascular death (4), the search for effective immunosuppressive regimens that do not rely on calcineurin inhibitors may result in improvement of long-term outcome, minimizing the systemic and allograft toxicity and maintaining the current low-acute rejection rates (5).

Avoidance and early withdrawal of calcineurin inhibitors under different induction protocols and adjuvant regimens are currently being tested for efficacy and safety in a variety of kidney transplant populations with different risk factors. One of the first attempts was described by Vincenti et al. (5) using induction with a 5-dose course of daclizumab and mycophenolate mofetil (MMF) at doses of $3 \mathrm{~g} /$ day for at least 6 months. This group presented an unacceptably high incidence of acute rejection but excellent graft function within the first year. However, only $14 \%$ of the recipients received grafts from living-related donors. Later, cyclosporine withdrawal after three months with maintenance of the sirolimus (SRL) and prednisone combination presented a low incidence of acute rejection and better graft function at one year when compared with patients maintained on low-dose cyclosporine, SRL and prednisone (6,7). Similar results were observed with cyclosporine withdrawal after 3 months in patients receiving MMF and prednisone $(8,9)$. In all of these studies a slightly higher incidence of acute rejection was observed after cyclosporine withdrawal. More recently, a calcineurin inhibitor-free regimen consisting of basiliximab induction followed by a combination of SRL, MMF and prednisone showed a less than $10 \%$ acute rejection rate and excellent one-year graft function (10). In that study, about $25 \%$ of the recipients received allografts from living-related donors.

Although the efficacy of calcineurin in- hibitor-free regimens still needs to be confirmed in higher risk populations, especially those without effective induction with polyclonal antibodies, on the basis of the studies conducted thus far, it appears that these regimens may be effective in a low-risk transplant population. We report here our initial experience with two calcineurin inhibitorfree regimens in a selected low-risk kidney transplant population.

\section{Subjects and Methods}

\section{Subjects}

Between January 6, 2001 and August 16, 2003, 92 recipients of first one-haplotype living-related kidney transplants were eligible for inclusion in this prospective single center study. Women of childbearing age were required to have a negative pregnancy test before administration of the medications under study and to practice medically approved birth control throughout the study and for 3 months after discontinuation of SRL. The protocol also required the patients to have a total white blood cell count $>4.0 \mathrm{x}$ $10^{9} / \mathrm{L}$, platelet count $>100.0 \times 10^{9} / \mathrm{L}$, fasting cholesterol $<350 \mathrm{mg} / \mathrm{dL}(<9.1 \mathrm{mmol} / \mathrm{L})$, and/ or fasting triglycerides $<500 \mathrm{mg} / \mathrm{dL}(<5.65$ $\mathrm{mmol} / \mathrm{L}$ ) during a pre-transplant screening evaluation. Patients were excluded if they had evidence of systemic infection or a history of clinically significant cardiac abnormalities or malignancy within 10 years. All patients were required to have had a negative T cell crossmatch. The local Ethics Committee approved the protocol and all patients were required to sign an informed consent form.

\section{Trial design}

We included in this trial only recipients of one-haplotype living-related allografts in order to obtain a more homogeneous population during the analysis of the primary 
end-points due to the relatively small number of patients allocated to each study group. Patients were enrolled and randomized before transplantation. During an initial phase patients were randomized to receive tacrolimus, azathioprine and prednisone (group I, GI), or two-doses dacluzimab induction (11) followed by a combination of MMF and prednisone (GII). Since an interim analysis revealed an excessive acute rejection rate among patients in GII, enrollment was interrupted on July 25, 2002 and a third group of patients was enrolled in a non-randomized fashion between January 23 and August 16, 2003 according to the same inclusion and exclusion criteria and treated with two-dose dacluzimab induction followed by a combination of MMF, SRL and prednisone (GIII).

\section{Immunosuppressive therapy}

GI patients received tacrolimus, $0.1 \mathrm{mg} /$ $\mathrm{kg}$, twice daily, administered within $24 \mathrm{~h}$ of graft revascularization. Tacrolimus doses were then adjusted to maintain trough blood concentrations between 10 and $20 \mathrm{ng} / \mathrm{mL}$ during the first month, between 8 and $15 \mathrm{ng} /$ $\mathrm{mL}$ during the second month, and between 5 and $8 \mathrm{ng} / \mathrm{mL}$ thereafter, measured by IMX System immunoassay using a specific monoclonal antibody against tacrolimus (IMX System, Abbott Diagnostics, Abbott Park, IL, USA). Patients also received fixed daily azathioprine doses of $2 \mathrm{mg} / \mathrm{kg}$. GII patients received two doses of $1 \mathrm{mg} / \mathrm{kg}$ daclizumab, one before graft revascularization and the other on day 14. MMF, $3 \mathrm{~g} /$ day, was initiated within $24 \mathrm{~h}$ and reduced to $2 \mathrm{~g} /$ day at 30 days. GIII patients received the same daclizumab treatment as GII, 2 g/day MMF and a 6-mg loading dose followed by $2 \mathrm{mg}$ fixed daily doses of SRL, all initiated within $24 \mathrm{~h}$. Whole blood SRL concentrations were measured by HPLC (12) after 7 and 14 days, and after 1, 2, 3, 6, 9, and 12 months. All patients received $1 \mathrm{~g}$ methylprednisolone before graft revascularization, followed by daily prednisone doses of $0.5 \mathrm{mg} \mathrm{kg}^{-1}$ day $^{-1}$ (maximum of $30 \mathrm{mg} /$ day) for 30 days. Prednisone was tapered to $20 \mathrm{mg} /$ day by month 2 , reaching $10 \mathrm{mg} /$ day between months 3 and 6 . No further reductions or steroid withdrawal were permitted by the protocol. All drugs were adjusted for safety and tolerability based on clinical findings.

Prophylaxis for Pneumocystis carinii pneumonia with trimethoprim-sulfamethoxazole was mandatory for all patients during the 12-month treatment period. None of the patients received prophylaxis for cytomegalovirus infection.

Unless contraindicated, patients with clinical and/or laboratory findings suggestive of acute rejection were required to undergo a graft biopsy to confirm the clinical diagnosis. A local pathologist graded the histological diagnoses according to the 1997 Banff criteria. Initial therapy for acute rejection consisted of a 3- to 5-day course of at least $500 \mathrm{mg}$ methylprednisolone daily. Patients who failed to respond to steroid therapy were treated with polyclonal antibodies. Delayed graft function was defined as a need for dialysis during the first post-transplant week. Graft loss was defined as physical loss due to nephrectomy, functional loss requiring maintenance dialysis for more than 8 weeks, or death with a functioning graft.

\section{Endpoints}

The primary efficacy endpoint was the rate of efficacy failure during the first 12 months after transplantation. Efficacy failure was defined as the first occurrence of a biopsy-confirmed acute rejection, graft loss or death. Secondary efficacy endpoints were: 1) the incidence, time and histological grade of first biopsy-confirmed acute rejection; 2) the incidence of all treated rejections, antibody-treated rejections and repeated rejections; 3 ) patient, graft and functioning (deathcensored) graft survival.

Safety analysis included hematology, 
biochemistry, lipid profile, and graft function measured by serum creatinine and calculated creatinine clearance (13). The occurrence of lymphoproliferative disease or other malignancies, serious adverse events, infections, and the frequency and reason for discontinuation of the drugs under study were also analyzed.

\section{Statistical analysis}

All patients in all groups were evaluated for the primary efficacy endpoints in an intention-to-treat analysis during the first 12 months after transplantation. Per protocol population was defined as the population completing 12 on randomized therapy. Descriptive statistics was provided for all vari- ables. To test the pre-transplantation equivalence of the two groups, the Student $t$-test was used for age, weight, height, vital signs, and laboratory determinations. The chisquare test was used to compare the distribution of nominal attributes such as sex, ethnic origin and medical history. The primary efficacy endpoints (rates of first biopsy-confirmed acute rejection episode, graft loss and death) were analyzed using the chisquare test. Hematologic and biochemical data were evaluated by analysis of covariance, with group as factor and the measurement at first visit after transplantation as covariate. The time to the first biopsy-confirmed acute rejection episode and the histological grade of the first acute rejection were evaluated by analysis of variance. Incidences

Table 1. Demographic characteristics of the transplant patients before and after the 12-month study.

\begin{tabular}{|c|c|c|c|c|}
\hline & Total $(\mathrm{N}=92)$ & $\mathrm{GI}(\mathrm{N}=38)$ & GII $(N=33)$ & GIII $(N=21)$ \\
\hline Age (years) & $36.0 \pm 11.1$ & $37.4 \pm 11.6$ & $33.0 \pm 10.0$ & $38.2 \pm 11.0$ \\
\hline Body mass index $\left(\mathrm{kg} / \mathrm{m}^{2}\right)$ & $23.4 \pm 4.1$ & $23.7 \pm 4.3$ & $22.7 \pm 3.5$ & $24.0 \pm 4.9$ \\
\hline \multicolumn{5}{|l|}{ Gender } \\
\hline Male & $55(60 \%)$ & $21(55 \%)$ & $22(67 \%)$ & $12(57 \%)$ \\
\hline Female & $37(40 \%)$ & $17(45 \%)$ & $11(33 \%)$ & $9(43 \%)$ \\
\hline \multicolumn{5}{|l|}{ Ethnicity } \\
\hline White & $76(83 \%)$ & $34(89 \%)$ & $27(82 \%)$ & $15(71 \%)$ \\
\hline Black & $15(16 \%)$ & $4(11 \%)$ & $6(18 \%)$ & $5(24 \%)$ \\
\hline Other & $1(1 \%)$ & $0(0 \%)$ & $0(0 \%)$ & $1(5 \%)$ \\
\hline \multicolumn{5}{|l|}{ Cause of end-stage renal disease } \\
\hline Hypertension & $31(33 \%)$ & $12(31 \%)$ & $15(45 \%)$ & $4(19 \%)$ \\
\hline Chronic glomerulonephritis & $22(24 \%)$ & $12(31 \%)$ & 7 (21\%) & $3(14 \%)$ \\
\hline Diabetes mellitus & $2(2 \%)$ & $0(0 \%)$ & $2(7 \%)$ & $0(0 \%)$ \\
\hline Others & $37(41 \%)$ & $14(38 \%)$ & $9(27 \%)$ & $14(67 \%)$ \\
\hline Time on dialysis (months) & $20.1 \pm 19.0$ & $16.7 \pm 10.8$ & $20.0 \pm 19.3$ & $26.5 \pm 27.0$ \\
\hline Panel reactive antibody $>5 \%$ & $7(8 \%)$ & $2(5 \%)$ & $2(6 \%)$ & $3(14 \%)$ \\
\hline Donor age (years) & $48.0 \pm 11.1$ & $48.3 \pm 10.8$ & $46.3 \pm 10.8$ & $50.0 \pm 12.5$ \\
\hline Delayed graft function & $1(5 \%)$ & $0(0 \%)$ & $0(0 \%)$ & $1(5 \%)$ \\
\hline Patients per-protocol at 12 months* & $67(73 \%)$ & $33(87 \%)$ & $16(48 \%)$ & $18(86 \%)$ \\
\hline Graft loss & $2(2 \%)$ & $1(2.6 \%)$ & $0(0 \%)$ & $0(0 \%)$ \\
\hline Death & $3(3.3 \%)$ & $1(2.6 \%)$ & $2(6.0 \%)$ & $0(0 \%)$ \\
\hline Withdrawn due to adverse events & $3(0.3 \%)$ & $0(0 \%)$ & $0(0 \%)$ & $3(14 \%)$ \\
\hline Withdrawn due to lack of efficacy* & $19(21 \%)$ & $3(8 \%)$ & $16(48 \%)$ & $0(0 \%)$ \\
\hline
\end{tabular}

Data are reported as means $\pm \mathrm{SD}$ or as number of patients with percent in parentheses. $\mathrm{GI}=$ group I patients immunosuppressed with tacrolimus, azathioprine, prednisone; group II (GII) = daclizumab (2 doses), mycophenolate mofetil, prednisone; group III (GIII) = daclizumab (2 doses), mycophenolate mofetil, sirolimus, prednisone.

${ }^{*} \mathrm{P}<0.05$ for GI vs Gll vs GIII (ANOVA). 
of treated rejection episodes (with or without biopsy confirmation), adverse events, infections, lymphoproliferative disease, and malignancy were compared by the Fisher exact test. Blood levels of tacrolimus and sirolimus are reported as means \pm SD. Patient and graft survival were calculated using Kaplan-Meier estimates and differences among groups were determined by the log-rank test.

All statistical tests were two-sided at the $5 \%$ level of significance. The $95 \%$ confidence intervals were calculated when possible. Data are reported as means \pm SD unless otherwise indicated.

\section{Results}

\section{Demographics and baseline characteristics}

The demographic characteristics of the allograft recipients were similar across treatment groups (Table 1). Overall this was a low-risk transplant population consisting predominantly of young, non-obese, white male recipients. Most of them were non-sensitized but mean time on dialysis was relatively long $(20.1 \pm 19.0$ months $)$. Only 1 patient in GIII developed delayed graft func- tion. At 12 months the proportion of patients receiving randomized therapy (per protocol population) was higher in GI and GIII compared to GII (87 vs 86 vs 48\%, $\mathrm{P}<0.01$, Table 1).

\section{Immunosuppression}

Mean doses and concentrations are shown in Table 2. In GI mean tacrolimus concentrations in whole blood were 14.6 $\pm 5.0,9.2 \pm$ 2.7, 7.6 \pm 3.2 , and 7.0 $\pm 2.4 \mathrm{ng} / \mathrm{mL}$ at $1,3,6$, and 12 months, respectively. Mean azathioprine doses were $129.0 \pm 26.7$ and $129.5 \pm$ $22.7 \mathrm{mg} /$ day at 1 and 12 months, respectively. In GII mean MMF doses were $2.8 \pm 0.4$, $2.2 \pm 0.4$ and $1.8 \pm 0.5 \mathrm{~g} /$ day at 14 and 30 days and at 12 months, respectively. In GIII mean trough SRL concentrations in whole blood were $7.4 \pm 4.4,6.4 \pm 4.0,6.0 \pm 3.5$, and $7.2 \pm 3.6 \mathrm{ng} / \mathrm{mL}$ at $1,3,6$, and 12 months, and mean MMF doses were $2.0 \pm 0.0,2.0 \pm$ 0.0 and $1.9 \pm 0.5 \mathrm{~g} /$ day at 14 and 30 days and at 12 months, respectively. Faster steroid taper was observed among GI patients between months 2 and 9 but no differences were observed at 1 year, with overall mean values of $9.7 \pm 4.2 \mathrm{mg} /$ day.

Table 2. Doses and blood concentrations of immunosuppressive drugs during the first 12 months after transplantation.

\begin{tabular}{|c|c|c|c|c|c|c|c|c|}
\hline \multirow[t]{2}{*}{ Day } & \multicolumn{3}{|c|}{$\mathrm{Gl}(\mathrm{N}=38)$} & \multicolumn{2}{|c|}{ GII $(N=33)$} & \multicolumn{3}{|c|}{ GIII $(N=21)$} \\
\hline & $\begin{array}{c}\text { TAC } \\
\text { dose } \\
\text { (mg/day) }\end{array}$ & $\begin{array}{c}\text { Blood TAC } \\
\text { concentration } \\
(\mathrm{ng} / \mathrm{mL})\end{array}$ & $\begin{array}{c}\text { PRED } \\
\text { dose } \\
\text { (mg/day) }\end{array}$ & $\begin{array}{l}\text { MMF } \\
\text { dose } \\
\text { (g/day) }\end{array}$ & $\begin{array}{l}\text { PRED } \\
\text { dose } \\
\text { (mg/day) }\end{array}$ & $\begin{array}{c}\text { Blood SRL } \\
\text { concentration } \\
(\mathrm{ng} / \mathrm{mL})\end{array}$ & $\begin{array}{l}\text { MMF } \\
\text { dose } \\
\text { (g/day) }\end{array}$ & $\begin{array}{c}\text { PRED } \\
\text { dose } \\
\text { (mg/day) }\end{array}$ \\
\hline 7 & $18.6 \pm 9.7$ & $20.4 \pm 6.2$ & $28.6 \pm 4.2$ & $3.0 \pm 0.2$ & $28.8 \pm 2.9$ & $5.4 \pm 2.0$ & $2.0 \pm 0.0$ & $28.7 \pm 2.7$ \\
\hline 14 & $18.6 \pm 6.1$ & $19.2 \pm 6.5$ & $28.0 \pm 4.0$ & $2.8 \pm 0.4$ & $28.5 \pm 3.2$ & $8.0 \pm 11.3$ & $2.0 \pm 0.0$ & $29.0 \pm 2.7$ \\
\hline 30 & $13.3 \pm 6.3$ & $14.6 \pm 5.0$ & $25.1 \pm 7.3$ & $2.2 \pm 0.4$ & $27.8 \pm 3.8$ & $7.4 \pm 4.4$ & $2.0 \pm 0.0$ & $28.1 \pm 3.7$ \\
\hline 60 & $10.7 \pm 5.5$ & $12.0 \pm 4.6$ & $17.8 \pm 5.0^{*}$ & $2.1 \pm 0.4$ & $24.3 \pm 8.0$ & $7.5 \pm 4.3$ & $2.0 \pm 0.2$ & $20.4 \pm 3.5$ \\
\hline 90 & $8.4 \pm 4.7$ & $9.2 \pm 2.7$ & $14.0 \pm 6.2^{*}$ & $2.0 \pm 0.5$ & $20.0 \pm 6.6$ & $6.4 \pm 4.0$ & $2.0 \pm 0.2$ & $14.8 \pm 6.0$ \\
\hline 180 & $6.6 \pm 4.2$ & $7.6 \pm 3.2$ & $8.2 \pm 2.5^{\star}$ & $2.0 \pm 0.5$ & $11.1 \pm 3.1$ & $6.0 \pm 3.5$ & $2.0 \pm 0.3$ & $10.1 \pm 1.2$ \\
\hline 270 & $6.5 \pm 3.8$ & $7.4 \pm 2.0$ & $8.5 \pm 3.2^{*}$ & $2.0 \pm 0.5$ & $10.3 \pm 2.3$ & $7.6 \pm 4.4$ & $1.9 \pm 0.4$ & $10.2 \pm 1.1$ \\
\hline 360 & $5.9 \pm 3.1$ & $7.0 \pm 2.4$ & $9.5 \pm 6.6$ & $1.8 \pm 0.5$ & $9.8 \pm 1.6$ & $7.2 \pm 3.6$ & $1.9 \pm 0.5$ & $9.9 \pm 0.5$ \\
\hline
\end{tabular}

Data are reported as means \pm SD. TAC = tacrolimus; PRED = prednisone; MMF = mycophenolate mofetil; $\mathrm{SRL}=$ sirolimus. For group definitions, see legend to Table 1.

${ }^{*} \mathrm{P}<0.01$ for GI vs GIl vs GIII (ANOVA). 
Efficacy

Primary efficacy end-point. At 12 months treatment failure was significantly higher in GII compared to GIII and GI (54.5 vs 24.0 vs $13.1 \%, \mathrm{P}<0.01$, Table 3), respectively. There was no significant difference between GI and GIII ( $\mathrm{P}=0.174)$.

Secondary efficacyend-points. There was a significant difference in the incidence of first biopsy-confirmed acute rejection among

Table 3. Primary and secondary efficacy end-points at 12 months.

\begin{tabular}{lccc}
\hline & GI (N=38) & GII (N=33) & GIII (N=21) \\
\hline Composite primary end-point* $^{*}$ & $5(13.1 \%)$ & $18(54.5 \%)$ & $5(24.0 \%)$ \\
BCAR* $^{*}$ & $4(10.5 \%)$ & $16(48.5 \%)$ & $5(24.0 \%)$ \\
Time to first BCAR (days) & $21.7 \pm 16.2$ & $59.1 \pm 42.0$ & $37.0 \pm 34.5$ \\
Severity of BCAR (N) & & & \\
IA & 1 & 6 & 4 \\
IB & 0 & 2 & 1 \\
IIA & 2 & 5 & 0 \\
IIB & 0 & 2 & 0 \\
III & 1 & 1 & 0 \\
Treated rejections & $6(15.8 \%)$ & $16(48.5 \%)$ & $8(38.1 \%)$ \\
Second rejection & $1(2.6 \%)$ & $3(9.0 \%)$ & $1(4.7 \%)$ \\
Antibody-treated rejection & $2(5.2 \%)$ & $2(6.1 \%)$ & $0(0 \%)$ \\
1-year patient survival & $(97.4 \%)$ & $(94.0 \%)$ & $(100 \%)$ \\
1-year graft survival & $(94.8 \%)$ & $(94.0 \%)$ & $(100 \%)$ \\
1-year functioning graft survival & $(97.4 \%)$ & $(100 \%)$ & $(100 \%)$ \\
\end{tabular}

Data are reported as number of patients with percent in parentheses and means \pm SD. $\mathrm{BCAR}=$ biopsy-confirmed acute rejection according to BANFF criteria. For group definitions, see legend to Table 1.

${ }^{*} \mathrm{P}<0.05$ for GI vs Gll vs GIII (ANOVA).

Table 4. Hematology, blood chemistry and renal function at 12 months.

\begin{tabular}{lccr}
\hline Parameters & GI $(\mathrm{N}=38)$ & GII $(\mathrm{N}=33)$ & GIII $(\mathrm{N}=21)$ \\
\hline Hemoglobin $(\mathrm{g} / \mathrm{dL})$ & $13.7 \pm 2.0$ & $13.3 \pm 2.4$ & $12.8 \pm 1.8$ \\
Hematocrit $(\%)$ & $41.2 \pm 6.0$ & $41.6 \pm 7.7$ & $39.8 \pm 5.4$ \\
White blood cells $\left(\mathrm{N} / \mathrm{mm}^{3}\right)$ & $8647 \pm 3678$ & $7780 \pm 2218$ & $7409 \pm 2734$ \\
Platelets $\left(10^{3} / \mathrm{mm}^{3}\right)$ & $206.2 \pm 44.8$ & $232.7 \pm 62.5$ & $228.0 \pm 61.2$ \\
Cholesterol $(\mathrm{mg} / \mathrm{dL})$ & $194 \pm 42$ & $197 \pm 34$ & $251 \pm 51^{*}$ \\
Triglycerides $(\mathrm{mg} / \mathrm{dL})$ & $165 \pm 97$ & $154.0 \pm 73$ & $289.0 \pm 151^{*}$ \\
Glucose $(\mathrm{mg} / \mathrm{dL})$ & $83 \pm 13$ & $89 \pm 33$ & $81 \pm 11$ \\
Creatinine $(\mathrm{mg} / \mathrm{dL})$ & $1.6 \pm 0.7$ & $1.7 \pm 0.8$ & $1.6 \pm 0.8$ \\
Creatinine clearance $(\mathrm{mL} / \mathrm{min})$ & $58.9 \pm 14.0$ & $56.9 \pm 16.4$ & $59.3 \pm 21.4$ \\
\hline
\end{tabular}

Data are reported as means \pm SD. For group definitions, see legend to Table 1 . ${ }^{*} \mathrm{P}<0.01$ for GIII compared to other groups (ANOVA). all groups $(\mathrm{P}<0.01$, Table 3$)$. GI patients showed a lower rate of acute rejection compared to GII or GIII patients (10.5 vs $48.5 v s$ $24.0 \%, \mathrm{P}<0.01)$. Addition of SRL reduced the incidence of acute rejection in GIII compared to GII $(24.0$ vs $48.5 \%, \mathrm{P}<0.05)$. Similar findings were observed when comparing the incidence of all treated rejections (15.8 vs 48.5 vs $38.1 \%, \mathrm{P}<0.01$ ). In patients of black ethnicity, the incidence of acute rejection was higher in GII compared to GI and GIII (83.3 vs 25 vs $20 \%, \mathrm{P}=0.055)$. Mean time to first biopsy-confirmed acute rejection was shorter in GI patients compared to GII and GIII (21.7 vs 59.1 vs 37 days, $P=0.092)$. No significant differences were observed in the severity of first biopsyconfirmed acute rejection, according to the BANFF criteria $(P=0.476)$ or of repeat rejections ( 2.6 vs 9.0 vs $4.7 \%, \mathrm{P}=0.482)$ and severe or steroid-resistant rejection that required treatment with antibodies (5.2 vs 6.1 vs $0.0 \%, \mathrm{P}=0.532$ ). Only one graft loss (GI) and 3 deaths ( 1 in GI and 2 in GII) were observed. Patient survival was comparable (97.4 vs 94.0 vs $100 \%$, ns) as also was graft survival (94.8 vs 94.0 vs 100\%, ns) and functioning graft survival (97.4 vs $100 v s$ $100 \%$, ns). Compared to GI and GIII, more patients in GII were switched to an alternative immunosuppressive regimen due to lack of efficacy ( $8 v s 48 v s 0 \%, \mathrm{P}<0.01$, Table 1$)$.

\section{Safety}

Hematology, biochemistry, and lipid profiles. At 12 months, mean hemoglobin and white blood cell and platelet counts were within the normal range, with no significant differences among groups. No significant differences were observed in mean glucose concentrations or hepatic function tests. Mean triglyceride and cholesterol concentrations were higher in GIII on day 14 and during month 1 , respectively, and these differences were maintained up to 12 months after transplantation (Table 4). 
Graft function. Overall, in the intentionto-treat population there were no differences in mean creatinine or calculated creatinine clearance at 12 months (Table 4). GIII patients who developed acute rejection showed worst graft function compared to patients without acute rejection $(2.4 \pm 1.3$ vs $1.3 \pm 0.3$ $\mathrm{mg} / \mathrm{dL}, \mathrm{P}<0.01$, Table 5). At 12 months a higher proportion of GI patients showed creatinine values less than $1.5 \mathrm{mg} / \mathrm{dL}$ compared to GII and GIII (75 vs 58 vs 57\%, P = 0.399 ). On the other hand, a high proportion of patients in all groups showed a delta creatinine of less than $0.5 \mathrm{mg} / \mathrm{dL}$ between months 6 and 12 (92 vs 94 vs 90\%, $\mathrm{P}=$ 0.462). Similar results were observed in the per-protocol population (Table 5).

Adverse events, infections and malignancies. Post-transplant diabetes mellitus was observed in $3(3.3 \%)$ patients, with no significant differences among groups (2.6 vs 6.1 vs $0.0 \%$, ns). Tolerability of MMF and/ or SRL was very good, as demonstrated by few dose changes and by the mean doses administered at 12 months. Overall inci- dence of cytomegalovirus infection was 4 (4.3\%), with no significant differences among groups (2.6 vs $0.0 v s$ 14.3\%, ns).

\section{Discussion}

One-haplotype living-related kidney transplants account for $28 \%$ of our annual transplant activity. Our attempt to develop a calcineurin inhibitor-free immunosuppressive regimen for a low-risk transplant population did not meet our main expectations, i.e., reducing allograft toxicity and keeping the current low-acute rejection rate. The control group, which received tacrolimus, azathioprine, prednisone, and no induction therapy showed a lower incidence of rejections, similar one-year renal function and patient and graft survival and very good tolerability and safety profile compared to MMF (GII) or to the MMF/SRL (GIII) combination. Apparently this control group did even better than similar populations in which acute rejection rates are about $30 \%$. Careful analysis of these results allowed us to identify possible

\begin{tabular}{|c|c|c|c|c|c|c|}
\hline \multirow{2}{*}{$\begin{array}{l}\text { Intention-to-treat } \\
\text { Acute rejection }\end{array}$} & \multicolumn{2}{|c|}{$\mathrm{GI}(\mathrm{N}=36)$} & \multicolumn{2}{|c|}{ GII $(N=31)$} & \multicolumn{2}{|c|}{ GIII $(N=21)$} \\
\hline & Yes $(\mathrm{N}=3)$ & No $(\mathrm{N}=33)$ & Yes $(N=15)$ & No $(N=16)$ & Yes $(\mathrm{N}=5)$ & No $(N=16)$ \\
\hline $\begin{array}{l}\text { Mean creatinine } \\
(\mathrm{mg} / \mathrm{dL})\end{array}$ & $1.6 \pm 0.5$ & $1.6 \pm 0.7$ & $1.9 \pm 0.7$ & $1.5 \pm 0.8$ & $2.4 \pm 1.3$ & $1.3 \pm 0.3^{*}$ \\
\hline $\begin{array}{l}\text { Patients with } \\
\mathrm{Cr}>1.5 \mathrm{mg} / \mathrm{dL}\end{array}$ & $25 \%$ & $75 \%$ & $42 \%$ & $58 \%$ & $43 \%$ & $57 \%$ \\
\hline $\begin{array}{l}\text { Patients with } \\
\qquad \Delta \mathrm{Cr}>0.5 \mathrm{mg} / \mathrm{dL}\end{array}$ & $8 \%$ & $92 \%$ & $6 \%$ & $94 \%$ & $10 \%$ & $90 \%$ \\
\hline Per-protocol & \multicolumn{2}{|c|}{$\mathrm{GI}(\mathrm{N}=33)$} & \multicolumn{2}{|c|}{ GII $(N=16)$} & \multicolumn{2}{|c|}{ GIII (N = 18) } \\
\hline Acute rejection & Yes $(N=2)$ & No $(N=31)$ & Yes $(N=0)$ & No $(N=16)$ & Yes $(\mathrm{N}=2)$ & No $(N=16)$ \\
\hline $\begin{array}{l}\text { Mean creatinine } \\
(\mathrm{mg} / \mathrm{dL})\end{array}$ & $1.6 \pm 0.8$ & $1.6 \pm 0.7$ & - & $1.5 \pm 0.8$ & $1.6 \pm 0.3$ & $1.3 \pm 0.3$ \\
\hline $\begin{array}{l}\text { Patients with } \\
\mathrm{Cr}>1.5 \mathrm{mg} / \mathrm{dL}\end{array}$ & $24 \%$ & $76 \%$ & $31 \%$ & $69 \%$ & $33 \%$ & $67 \%$ \\
\hline $\begin{array}{l}\text { Patients with } \\
\qquad \Delta \mathrm{Cr}>0.5 \mathrm{mg} / \mathrm{dL}\end{array}$ & $9 \%$ & $91 \%$ & $6 \%$ & $94 \%$ & - & $100 \%$ \\
\hline
\end{tabular}

Data are reported as means $\pm \mathrm{SD}$ or as percent. $\Delta \mathrm{Cr}>0.5 \mathrm{mg} / \mathrm{dL}=$ comparing values at 6 and 12 months (Ref. 3). For group definitions, see legend to Table 1.

${ }^{*} \mathrm{P}<0.01$ comparing mean creatinine values of patients with or without acute rejection in GIII (ANOVA). 
reasons, namely: 1) inappropriate induction therapy in both GII and GIII, 2) a premature reduction of the MMF dose in GII, 3) insufficient SRL exposure in GIII, 4) lack of prospective serum mycophenolic acid (MPA) measurement in the absence of a calcineurin inhibitor, and 5) ethnicity.

Perhaps full 5-dose courses of daclizumab would be ideal in a calcineurin-inhibitor free regimen even in this low-risk transplant population. Two $1-\mathrm{mg} / \mathrm{kg}$ doses of daclizumab produce IL-2 receptor saturation for about 10 weeks (11). In GII and GIII, 30 and 29\% of rejections occurred after week 8 , respectively. However, in a similar study in which Vincenti et al. (14) employed a regimen with five doses of daclizumab, the biopsy-proven acute rejection was diagnosed in $21 \%$ at day 30 and $38 \%$ at day 90 .

Another shorter alternative strategy includes 2 doses of $2 \mathrm{mg} / \mathrm{kg}$ daclizumab, which produce effective antibody concentrations and prolonged saturation of IL-2R $\alpha$ on circulating lymphocytes (14).

Early reduction in MMF doses at 15 days may also have contributed, at least in part, to the higher incidence of acute rejection, particularly in GII, taking into account the excellent tolerability observed in the absence of a calcineurin inhibitor. Vincenti et al. (5) employed doses of $3 \mathrm{~g}$ for at least 6 months. In the present study, the addition of a 2-mg fixed dose of SRL, which resulted in mean trough concentrations of 6-8 $\mathrm{ng} / \mathrm{mL}$, reduced the incidence of acute rejection from 48.5 to $24 \%$ ( $\mathrm{P}=0.07)$. Still, this rate of acute rejection is higher than the $6.4 \%$ observed by Flechner et al. (10) in a low-risk population. In that trial, Flechner et al. used induction with basiliximab (two doses of $20 \mathrm{mg}$ on days 0 and 4) and targeted SRL trough concentrations to $10-12 \mathrm{ng} / \mathrm{mL}$. Contrasting with the excellent MMF tolerability observed in the present study (Table 2), about one third of the patients in the cited study (10) did not tolerate $2 \mathrm{~g}$ of MMF and mean serum MPA trough concentrations were around $5 \mathrm{mg} / \mathrm{L}$, indicating that higher SRL trough concentrations may be involved in both efficacy and toxicity (10). There is a growing body of data suggesting that MPA serum therapeutic drug monitoring may be useful especially in the absence or reduced doses of calcineurin inhibitor (15). Unfortunately, target therapeutic concentrations under these circumstances have not been identified or tested prospectively in large trials. Finally, patients of black ethnicity have been considered to be at high immunological risk to develop acute rejection and inferior graft survival. The higher incidence of rejection observed in patients of black ethnicity in GII suggests that a better HLA matching offered by living-related one-haplotype kidney allografts does not reduce substantially the risk for acute rejection. These patients may still need a calcineurin inhibitor-based immunosuppressive regimen to present low rates of acute rejection (16).

The higher and later occurrence of acute rejection episodes mitigated the benefit of the calcineurin inhibitor-free regimens (GII and GIII) for graft function. At 1 year, mean creatinine values did not differ among groups. Moreover, in GII and GIII, patients with acute rejection showed higher mean creatinine levels than those without acute rejection. The percentage of patients with good renal function at 1 year (creatinine values less than $1.5 \mathrm{mg} / \mathrm{dL}$ ) was similar for the three groups in the per-protocol population but higher in the tacrolimus group in the intention-to-treat population. In addition, despite the higher incidence of acute rejection in GI and GII, the incidence of antibody-treated rejection and repeated rejection was similar in all three groups, suggesting that the rejections which lead to a change in the immunosuppressive therapy resulted in sustained impaired graft function, independently of the histological grades and of resistance or not to steroid treatment. The lack of a 1-year biopsy, however, precludes more conclusive analysis. Interestingly, sta- 
bility of graft function between months 6 and 12 was observed in a high proportion of patients (intention-to-treat or per-protocol) in all three groups.

The safety profile of all three regimens was benign, with low incidences of posttransplant diabetes mellitus and cytomegalovirus disease, although a typical increase in cholesterol and triglyceride concentrations was observed in GIII patients.

Further development of an effective calcineurin inhibitor-free regimen for one-haplotype living-related kidney transplant re- cipients should exclude patients of black ethnicity and may need full-induction therapy, perhaps with depleting agents, and use of SRL and MMF at controlled concentrations. In summary, the combination of tacrolimus, azathioprine and prednisone appears to be ideal for these low-risk kidney transplant patients. Alternative schedules allowing minimization or elimination of either calcineurin inhibitors or prednisone should be taken into account for selected patients with recognized risk factors for graft loss and/or death.

\section{References}

1. Siddiqi N, McBride MA, Hariharan S. Similar risk profiles for posttransplant renal dysfunction and long-term graft failure: UNOS/OPTN database analysis. Kidney Int 2004; 65: 1906-1913.

2. Meier-Kriesche HU, Kaplan B. Waiting time on dialysis as the strongest modifiable risk factor for renal transplant outcomes: a paired donor kidney analysis. Transplantation 2002; 74: 1377-1381.

3. Hariharan S, McBride MA, Cherikh WS, Tolleris CB, Bresnahan BA, Johnson CP. Post-transplant renal function in the first year predicts long-term kidney transplant survival. Kidney Int 2002; 62: 311-318.

4. Meier-Kriesche HU, Baliga R, Kaplan B. Decreased renal function is a strong risk factor for cardiovascular death after renal transplantation. Transplantation 2003; 75: 1291-1295.

5. Vincenti F, Ramos E, Brattstrom C, Cho S, Ekberg H, Grinyo J, et al. Multicenter trial exploring calcineurin inhibitors avoidance in renal transplantation. Transplantation 2001; 71: 1282-1287.

6. Gonwa TA, Hricik DE, Brinker K, Grinyo JM, Schena FP. Improved renal function in sirolimus-treated renal transplant patients after early cyclosporine elimination. Transplantation 2002; 74: 1560-1567.

7. Kreis H, Oberbauer R, Campistol JM, Mathew T, Daloze P, Schena FP, et al. Long-term benefits with sirolimus-based therapy after early cyclosporine withdrawal. J Am Soc Nephrol 2004; 15: 809817.

8. Abramowicz D, Manas D, Lao M, Vanrenterghem Y, del Castillo D, Wijngaard $\mathrm{P}$, et al. Cyclosporine withdrawal from a mycophenolate mofetil-containing immunosuppressive regimen in stable kidney transplant recipients: a randomized, controlled study. Transplantation 2002; 74: 1725-1734.

9. Smak Gregoor PJ, de Sevaux RG, Ligtenberg G, Hoitsma AJ, Hene RJ, Weimar W, et al. Withdrawal of cyclosporine or prednisone six months after kidney transplantation in patients on triple drug therapy: a randomized, prospective, multicenter study. J Am Soc Nephrol 2002; 13: 1365-1373.

10. Flechner SM, Goldfarb D, Modlin C, Feng J, Krishnamurthi V, Mastroianni B, et al. Kidney transplantation without calcineurin inhibitor drugs: a prospective, randomized trial of sirolimus versus cyclosporine. Transplantation 2002; 74: 1070-1076.

11. ter Meulen CG, Baan CC, Hene RJ, Hilbrands LB, Hoitsma AJ. Two doses of daclizumab are sufficient for prolonged interleukin-2Ralpha chain blockade. Transplantation 2001; 72: 1709-1710.

12. Di Marco GS, de Andrade MC, Felipe CR, Alfieri F, Gooding A, Silva HT Jr, et al. Determination of sirolimus blood concentration using high-performance liquid chromatography with ultraviolet detection. Ther Drug Monit 2003; 25: 558-564.

13. Cockcroft DW, Gault MH. Prediction of creatinine clearance from serum creatinine. Nephron 1976; 16: 31-41.

14. Vincenti F, Pace D, Birnbaum J, Lantz M. Pharmacokinetic and pharmacodynamic studies of one or two doses of daclizumab in renal transplantation. Am J Transplant 2003; 3: 50-52.

15. Mourad M, Wallemacq P, Konig J, de Frahan EH, Eddour DC, De Meyer M, et al. Therapeutic monitoring of mycophenolate mofetil in organ transplant recipients: is it necessary? Clin Pharmacokinet 2002; 41: 319-327.

16. Ferreira AN, Machado PG, Felipe CR, Motegi SA, Hosaka BH, Tanaka MK, et al. Concentration-controlled use of sirolimus associated with reduced exposure of cyclosporine in black recipients of primarily living renal allograft donors: 12-month results. Clin Transplant 2005; 19: 607-615. 